\title{
A NATUREZA E O LUGAR HABITADO COMO ÂMBITOS DA EXPERIÊNCIA ESTÉTICA: novos entendimentos da relação ser humano - ambiente
}

\author{
Andréia Aparecida Marin* \\ Kátia Maria Kasper**
}

RESUMO: A percepção que o ser humano tem da natureza e do espaço habitado é marcada pela imaginação, pela afetividade, pela memória e pela sensibilidade estética. $\mathrm{O}$ significado da experiência estética está presente tanto nas construções do lugar habitado quanto na contemplação dos ambientes preservados. No presente ensaio, propomos um caminho reflexivo que evidencia essa necessidade estética do humano, focando-a nas categorias natureza e espaços do cotidiano como âmbitos de vivência. Tecemos considerações sobre os possíveis significados da teoria estética para a educação ambiental. Para tanto, partimos do resgate de referenciais teóricos da fenomenologia e do campo da filosofia estética, que incluem Merleau-Ponty, Bachelard, Dufrenne e Quintás.

Palavras-chave: Experiência Estética; Educação Ambiental; Percepção Ambiental.

\section{NATURE AND SPACE AS SCOPES FOR AESTHETIC EXPERIENCE:}

new understanding of the relationship human being - environment

ABSTRACT: Human being's perception of nature and of the inhabited space is marked by imagination, affectivity, memory and aesthetic sensibility. The meaning of aesthetic experience is present in the buildings of the inhabited place as well as in the sight of preserved environments. In the present paper we propose a reflective way that makes evident this aesthetic need of mankind, focusing it in the categories of natural and daily spaces as scopes of life experience. We consider the possible meanings of aesthetic theory for environmental education. Thus we start at the recovery of theoretical references of phenomenology and of aesthetic philosophy that include Merleau-Ponty, Bachelard, Dufrenne, and Quintás.

Keywords: Aesthetic Experience; Environmental Education; Environmental Perception.

* Doutora em Ecologia e Recursos Naturais pela Universidade Federal de São Carlos UFSCar. Professora do Programa de Pós-Graduação em Educação da Universidade Federal do Paraná - UFPR. E-mail: aamarin@ufpr.br.

* Doutora em Educação pela Universidade Estadual de Campinas - UNICAMP. Professora do setor de Educacão da Universidade Federal do Paraná - UFPR. E-mail: katiakasper@uol.com.br. 


\section{INTRODUĈ̣̃O}

A complexidade do ser humano se reflete nas diversas formas com que se relaciona com o mundo. As percepções construídas em suas vivências vão além da compreensão racional a respeito dos fenômenos, comportando um estrato pré-intelectual nutrido especialmente da sensibilidade estética, da imaginação e da criação poética. Dessa forma, discutir a percepção ambiental pressupõe tratar da dimensão estética do ser humano.

A experiência de interação do ser humano com a natureza e os lugares habitados é um apelo à experiência estética e à criatividade. A relação com o ambiente é necessariamente uma relação estética. Note-se que em seus espaços cotidianos estão claramente presentes a busca pelo belo natural e os traços da criação de sublimidades, repletas de significações que acabam por configurar os modos de viver e as construções culturais dos grupos que os compartilham.

Já há algum tempo vem se discutindo a percepção ambiental em conexão com a percepção estética. Seus fundamentos comuns evidenciados trazem novas perspectivas para a educação ambiental, no sentido mais amplo e complexo que esta vem tomando nos últimos anos. Esse sentido é marcado pela necessidade de formação integral do ser humano, que envolva não somente suas dimensões intelectivas, mas também sua emotividade e sua capacidade imagética e criativa. Nesse sentido, a vivência da experiência estética é de fundamental importância. É por meio dela que o ser humano relaciona-se com o mundo, não com o objetivo de dissecá-lo e sistematizar explicações sobre fenômenos, mas como um campo de experiências possíveis, de encontro com as coisas e com os outros e de possibilidade de criação de novos modos de viver e de novas subjetividades. Nessa forma de interação com o meio, perde espaço a supremacia da razão, típica do pensamento clássico moderno: “(...) se na experiência prática há um nítido predomínio do conceitual sobre o afetivo, da razão sobre o sentimento e a imaginação, o mesmo não ocorre na experiência da beleza; aqui equilibram-se o sentir e o pensar" (DUARTE JR., 1998, p. 56).

A estesia relaciona-se, portanto, com a capacidade humana de transcender o olhar imediatista sobre as coisas. O Homo aestheticus é alguém que está emaranhado nas teias do mundo. Percebe-o poeticamente, 
aceitando sua complexidade, em vez de objetivá-lo. Não há, pois, como falarmos de percepção se estamos pretensamente descolados do mundo, numa atitude puramente analítica. Somos a partir de nossa presença no mundo, das experiências estéticas que ele nos proporciona. Se estamos imersos e somos, assim, atravessados pelo mundo, pressupomos a diluição da dicotomia sujeito-objeto, motivo pelo qual as reflexões da fenomenologia podem nos auxiliar no entendimento dos significados da poetização do mundo.

A poética e a simbologia da arte são expressões intimamente próximas da intensidade vivenciada na experiência estética do mundo. A construção poética não requer enquadramentos conceituais nítidos, não pressupõe a forma definitiva, de maneira que pode expressar a fluidez da percepção estética, potencial ainda mais enriquecido pela capacidade imagética. No pensamento bachelardiano, a imaginação tem papel de grande importância na medida em que estimula a composição de imagens belas que superam o percebido.

O lugar vivido é a dimensão mais reveladora da existência humana, um campo de jogo definido, que abriga o belo natural e as múltiplas manifestações da criatividade humana. A percepção desse espaço de vivência é, portanto, fonte constitutiva do ser humano. Isso justifica nossa preocupação aqui em pensar a necessidade estética do humano e a forma como a natureza e o espaço podem representar âmbitos da experiência estética. De outro lado, os espaços construídos podem significar causas do embrutecimento dos sentidos e enfraquecimento dos laços afetivos, se não se atentar para o cuidado com o desenho dos lugares habitados, as histórias de vida e as subjetividades que aí se constituem.

No presente trabalho, construímos um caminho reflexivo que parte da elucidação de uma nova forma de pensar a relação ser humanoambiente, para além da lógica científica e tecno-desenvolvimentista, característica dos discursos ambientais modernos, enfatizando a necessidade de recuperação da estesia. Focamos, para tanto, o questionamento das condições de vivência da experiência estética nos grandes centros urbanos e nos modos de viver da atualidade, chegando, assim, aos desafios da educação ambiental na tentativa de superação de um possível embrutecimento dos sentidos neles operado. 


\section{A PERCEPC̣̃̃O ESTÉTICA, SOB O OLHAR DA FENOMENOLOGIA}

Enquanto as bases fenomenológicas da percepção estética ficam bastante evidenciadas na obra de Dufrenne - a partir da análise da experiência estética -, podemos recorrer a Merleau-Ponty, Bachelard e Quintás para pensarmos a propósito da percepção do mundo e, mais especificamente, da natureza. Merleau-Ponty contribui para entendermos a ressignificação do mundo vivido a partir da superação da síntese intelectualista, enquanto em Bachelard encontramos a clareza da poetização dos espaços cotidianos e, por último, em Quintás, a arte como forma de plasmar âmbitos e a sensibilidade estética como geradora de novos olhares sobre os espaços de vivência.

Para Dufrenne, a necessidade do belo é reflexo da necessidade que o ser humano tem de sentir-se no mundo, de maneira que a experiência estética, mesmo que não revele sua vocação, traduz a experiência de sua relação profunda com o mundo: “(...) estar no mundo não é ser coisa entre as coisas, é sentir-se em casas entre as coisas" (DUFRENNE, 2002, p. 25).

Sentir-se em casa entre as coisas pressupõe uma recriação da relação do ser humano com o ambiente, uma vez que há um nítido distanciamento operado por uma forma de interação, inspirada na modernidade clássica, que destaca a consciência das coisas, cria delas uma representação que passa a mediar a relação sujeito-objeto. Nas obras de Merleau-Ponty há um esforço evidente de superação dessa destituição de significados do mundo vivido e dessa dicotomia sujeito-objeto, operadas pelo pensamento científico clássico. Para ele, "a ciência manipula as coisas e renuncia a habitá-las” (MERLEAU-PONTY, 1984, p. 85). Por isso sua defesa da necessidade de encarnar o sujeito no mundo.

Em Fenomenologia da percep̧ão (MERLEAU-PONTY, 1999, p. 26), Marleau-Ponty denuncia a ingenuidade das pretensões da ciência, afirmando que o significado possível do mundo se dá pela percepção que pressupõe a inserção incondicional nesse mundo: "construímos a percepção com o percebido (...). Estamos presos ao mundo e não chegamos a nos destacar dele para passar à consciência do mundo”. O destaque de uma consciência capaz de um juízo sobre o mundo percebido e de buscar a exata definição das coisas confere, portanto, o caráter ingênuo da concepção analítica da percepção. O mundo sensível 
comporta indeterminações, constituintes da visão originária, que se perdem diante dessa busca por definições precisas.

O conceito de percepção que deriva dessa diferença entre mundo representado e mundo vivido é evidente: se, para os clássicos, a percepção é tão-somente a leitura do concreto e do sensível para serem processados pelo pensamento, em Merleau-Ponty, ela ganha um caráter de fluidez sensível que reabilita a vitalidade e a validade do mundo percebido. A consequência disso é uma crítica que não é necessariamente uma negação da ciência, mas de toda forma de dogmatismo científico: "O concreto e o sensível conferem à ciência a tarefa de uma elucidação interminável, e daí resulta que não se pode considerá-los, à maneira clássica, como uma simples aparência destinada a ser superada pela inteligência científica” (MERLEAU-PONTY, 2004, p. 7). É nesse sentido que Merleau-Ponty afirma, na Fenomenologia da percepção:

A percepção não é uma ciência do mundo, não é nem mesmo um ato, uma tomada de posição deliberada; ela é fundo sobre o qual todos os atos se destacam e ela é pressuposta por eles. O mundo não é um objeto do qual possuo comigo a lei de constituição; ele é o meio natural e o campo de todos os meus pensamentos e de todas as minhas percepções explícitas. A verdade não "habita" apenas o "homem interior", ou, antes, não existe homem interior, o homem está no mundo, é no mundo que ele se conhece. Quando volto a mim a partir do dogmatismo do senso comum ou do dogmatismo da ciência, encontro não um foco de verdade intrínseca, mas um sujeito consagrado ao mundo". (MERLEAU-PONTY, 1999, p. 6)

O objeto não é, por consequência, uma fonte de qualidades sensíveis que são reunidas e ganham sentido por uma síntese intelectual. O objeto não tem, na radicalidade, existência de fato, sendo só mais uma nuance do jogo complexo de interações do sujeito com o mundo. Daí a defesa de uma síntese perceptiva que fuja das reduções do intelectualismo.

A base da experiência estética descrita por Dufrenne parece sinalizar para essa síntese perceptiva: "se situa na origem, naquele ponto em que o homem, confundido inteiramente com as coisas, experimenta sua familiaridade com o mundo" (DUFRENNE, 2002, p. 30-31). O mundo se revela a partir desse encontro e o ser humano pode, dessa forma, pela fé perceptiva, ler as imagens que ele então lhe oferece e expressá-las livres de formalismos conceituais.

Essa capacidade de experiência poética do mundo justifica a inclinação emocional do ser humano ao belo, uma vez que este se pode 
instalar no pré-formal, embora não possa carecer de matéria, não estando num nível de abstração que nos impede a experiência intencional. Ele está necessariamente encarnado em objetos estéticos (DUFRENNE, 2002, p. 39).

\section{EXPERIÊNCIA ESTÉTICA E PERCEPÇ̃̃O AMBIENTAL}

$\mathrm{Na}$ cultura ocidental, o ser humano rompe tanto com seu ambiente quanto com sua história, fragilizando muitas vezes a condição fluida que deveria permear essa relação. O formalismo que se enraíza nas ciências é o mesmo que engessa sua espiritualidade, sua emotividade e sua relação com o mundo e com a história. A dificuldade de lidar com a pré-intelectualidade, com o pré-formal, incutida pela lógica do pensamento cientificista, cristaliza as potencialidades do ser, sacrificando a gênese de novas formas de interação com o ambiente, com os outros, e de novos modos de viver.

A necessidade de superação do formalismo tem seu espaço no campo das artes, por exemplo, no movimento impressionista, que traz na deformação dos objetos, na ausência de linhas definidas, um apelo para a percepção livre, segundo Dufrenne (2002, p. 229), por um "contato original com o mundo, uma verdade primeira do percebido". O mesmo autor apresenta também Bachelard como um exemplo de fuga das racionalidades, quando se aventura numa epistemologia não-cartesiana e expressa uma poética aberta ao mundo, em que está permitida uma ligação entre real e imaginário. Dialogando com a Poética do espaço bachelardiana, reivindica da arquitetura a construção do sentido vital e da beleza ingênua do babitat humano, livre de formalismos paralisantes.

O mundo que forja a técnica é um mundo no qual o homem ainda pode se sentir em casa, se a educação e o regime social lhe permitem tornar-se o sujeito da cultura ao invés de ser o objeto, porque é um mundo que, longe de dissimular ou de destruir a natureza, ainda a revela... (DUFRENNE, 2002, p. 236).

É essa percepção que capta a fluidez e a dinamicidade das coisas que a experiência estética pode ensinar e, dessa forma, levar o ser humano a ressignificar sua relação com o ambiente, com o lugar habitado, com a natureza. Nesse sentido, a experiência estética associada à reconstituição histórica da relação com o lugar pode ser um amplo caminho para a ressensibilização ambiental. 


\section{OS ÂMBITOS DE ENCONTRO, SEGUNDO QUINTÁS}

$\mathrm{Na}$ sua teoria estética, Quintás (1992) não enfatiza a relação entre sujeito-objeto, não trabalhando na perspectiva de encontro fusional entre as coisas, mas entre "âmbitos da realidade", mantendo assim a mesma base existencialista. No cerne de suas reflexões está a criatividade, que permite ao ser humano entrar em jogo com as realidades do meio ambiente. A partir desse jogo, criam-se "vínculos fecundos" com o ambiente (QUINTÁS, 1992, p. 14).

Os âmbitos de realidade de Quintás são todos os espaços, acontecimentos e relações que tecem a vida humana, campos de interação e campos de sentido. Concretamente, pode-se dizer que signifiquem desde espaços cotidianos (casa, paisagem, jardim) até imagens representativas (declinar do outono, monumento, obra artística). A arte, em sua teoria, é justamente o caminho que permite acessar a vivência desses âmbitos: “(...) o autêntico meio ambiente do homem não está formado por objetos justapostos, mas por âmbitos integrados. É esse meio ambiente cheio de eficiência, dinamismo e sentido que a arte encarna e revela" (QUINTÁS, 1992, p. 19).

No espaço do encontro, nunca se está individualizado, de maneira que naturalmente se estabelecem situações de dialogicidade. Existir pressupõe abrir-se, dispor-se à troca de sentimentos e reflexões, de diálogos constantes com as coisas e com os outros, que representam motivação criadora. As situações monológicas geram objetos acabados, suficientes. Do espaço dialógico surgem, segundo o autor, realidades ambitais, "inobjetivas" espaços lúdicos, campos de jogo nos quais todo ser humano pode "mergulhar" de forma criadora (QUINTÁS, 1992, p. 42).

Quintás sugere uma revisão dos significados da atividade contemplativa. No lugar de ser tomada como sinônimo de receptividade e passividade, representa a forma ativa de se conseguir a unidade ambiente-interioridade. A contemplação exige uma entrega criadora, dá vida ao novo e expressão a novos âmbitos, enquanto que o olhar superficial condiciona o artista fora da realidade vivida e, portanto, a uma ação reprodutivista. Ela se dá, dessa forma, num momento de imersão participativa, de transcendência do caráter objetivo, formal, das realidades, de abertura incondicional. 


\section{A NATUREZA E O ESPAC̣O COMO ÂMBITOS DA EXPERIÊNCIA ESTÉTICA}

Dessa interpretação da contemplatividade como postura ativa comunga Schopenhauer (2001), para quem contemplar é participar da vontade do belo, ceder à força da natureza que chama o ser humano à contemplação. A intuição, ativa no estado contemplativo, permite ao contemplador captar das obras de arte a mesma visão intuitiva que teve seu criador. É no estado contemplativo que o sujeito se mistura com o mundo e que os fenômenos se revelam: "apenas pela pura contemplação a dissolver-se completamente no objeto é que as idéias são apreendidas. (...) Toda contemplação exige pura disposição objetiva, isto é, esquecimento completo da própria pessoa” (SCHOPENHAUER, 2003, p. 61).

A forma como nos encontramos emaranhados às coisas não pode ser expressa pelo puro uso dos conceitos, na medida em que são percebidos numa dimensão pré-intelectual. Para Dufrenne (2002, p. 75), "existir não é somente um destino comum ao homem e às coisas, o homem existe com as coisas e tanto mais profundamente, quanto mais profundamente ele está junto com elas”. Isso permite a compreensão de que a percepção estética possibilita a redescoberta da conaturalidade do humano com a natureza: “(...) o céu estrelado não me diz que eu seja razão ou capaz de razão. Mas ele me diz, ao menos, que essa presença imensa é uma presença para mim, que eu estou, portanto, secretamente ajustado a essa imensidade" (DUFRENNE, 2002, p. 77).

Dufrenne trata da diferença entre objetos estéticos e inestéticos. Para ele, o objeto inestético é aquele que não chega a expressar algo que possa ser recebido pelas vias do sentimento, que é a via do espírito a colocar o ser humano em contato com as coisas. Nesse contexto, a natureza é plenamente dotada de elementos estéticos: paisagens, árvores, flores, vegetação nas matas, meandros de um rio. Todas essas imagens nos capturam, revelando uma natureza comum conosco. Ainda mais, não só a natureza inumana é estetizável, mas também tudo que se mistura a ela sem "desorná-la": “(...) uma paisagem humana [...] ou semi-humana (um parque, uma vereda de montanha, uma aldeia à maneira de ninho de águia) se oferece tão intensamente à experiência estética, quanto uma paisagem totalmente inumana, montanha ou deserto" (DUFRENNE, 2002, p. 70).

Ainda com relação ao belo natural, Dufrenne enfatiza que "a natureza não cessa de improvisar” (DUFRENNE, 2002, p. 62), de forma 
que seu contorno não é fixo e o efeito estético está em constante mudança. A imprevisibilidade de um mundo presente e mutável, e não representado, coloca o ser humano diretamente em contato com o sensível não premeditado do mundo: “(...) diante do espetáculo natural, somos envolvidos e integrados no devir natural do mundo" (DUFRENNE, 2002, p. 63). A natureza não somente desperta o instinto biofílico do humano, mas é, para ele, uma fonte para seus desejos de vislumbrar o belo e de vivenciar a intencionalidade.

No prazer que eu sinto numa paisagem, do alto do cume de uma montanha, acaso posso dizer que parte cabe ao frescor do ar, ao perfume das flores silvestres, à satisfação de ter galgado a montanha e afirmado, nessa jornada, minha vontade de domínio? (...) É, porém, mais na superfície que nós nos comunicamos com o objeto natural e que estamos como que misturados a ele. (DUFRENNE, 2002, p. 63)

É pela natureza que o ser humano se sente restituído a si mesmo, parentesco revelado por uma forma de alteridade como um atravessamento do outro, de forma que a natureza possa ser para ele identidade, linguagem e poesia: "é com essa condição que a natureza me reenvia minha própria imagem; que seus abismos me significam meus próprios infernos; suas tempestades, minhas paixões; seus céus, minha nobreza; suas flores, minha inocência" (DUFRENNE, 2002, p. 68). É dessa forma que a experiência estética que a natureza suscita lhe dá uma "lição de estar no mundo" (DUFRENNE, 2002, p. 76).

A natureza atrai o ser humano até mesmo em suas faces superficialmente trágicas. Quando se analisa a obra de Bachelard $A$ água e os sonhos (1997), vê-se com detalhes a descrição de possíveis significados que as águas oceânicas têm para o humano, com todas as suas nuances de mistério e perigo. No entanto, o que parece amedrontador e negativo é recebido pelo contemplador como objeto estético, na medida em que o envolve num desejo de participação que transforma infinitude e poder em fluidez e sublimidade. Também Dufrenne apresenta um exemplo assim: “(...) quando a natureza é violenta como na tempestade, ela não é trágica, mesmo que os seus efeitos possam sê-lo, porque ela não entra em guerra com o destino ou contra si, ela é sublime (DUFRENNE, 2002, p. 75). É essa força implícita na nossa relação com a natureza, capaz de diluir a negatividade de suas faces trágicas, que revela a necessidade que temos de 
mergulhar nossos sentidos em vivências estéticas e de carregar as expressões da natureza e as significações que construímos a partir dessas vivências, para a construção de nossos espaços vividos cotidianamente.

Ribon, na obra $A$ arte e a natureza (1991), defende que a absoluta identidade da natureza e do ser humano é refletida na arte. A natureza, além de carregar um repertório de signos compreendidos por toda parte, é também um espaço aberto aos sentimentos humanos, a seus desejos e temores, nostalgias e alegrias, repleto de imagens que ganham contornos afetivos e existenciais. Sem esses contornos, a percepção daria ao ser humano um conjunto de formas significantes apenas em vista de suas necessidades práticas. A percepção estética, por outro lado, o remete a uma beleza natural que só pode ser apreendida pelo viés da cultura artística. Nesse contexto, o autor expressa com riqueza a superação de formalismos e a libertação poética que a experiência do belo pode proporcionar:

Voltamos aos locais de beleza natural como aos lugares de uma peregrinação, de uma presença, de um refúgio. Então descobrimos aí aquilo que a negligência intelectual de uma cultura nos fizera esquecer: a identidade do eu e do mundo, do sujeito e do objeto, do espírito e da natureza, que um dualismo ilusório separava... (RIBON, 1991, p. 41).

Várias formas de criação artística, especialmente aquelas presentes no impressionismo e no pós-impressionismo de Cézanne, revelam a natureza. Expressando as novas significações configuradas na sua mistura com ela, o artista fala de sua imensidão. O que ele coloca em sua criação parece ser a emoção vibrante do momento em que ela é vivenciada, traduzindo-a em dissolução de toda forma e consistência, em luminosidade e fluidez. Ora, onde mais se poderá vivenciar tal fluidez senão em uma natureza livre de conceitos? Qual forma definitiva ou cor homogênea é encontrada numa floresta? Quais sons se repetem uniformemente se a floresta é ouvida sinoticamente? Quais interações do humano com o mundo não trazem em si complexidade e dinamicidade?

As vivências estéticas da natureza e dos lugares construídos habitados jamais se perdem em nossos momentos contemplativos, mas se tornam motivo de criação e matéria de laços que com eles estabelecemos, ressoando nos momentos nostálgicos e nos devaneios e nas construções imaginárias. Aqui se pode fazer um recorte para a apresentação do termo 
criado por Bachelard (1993) - topofilia -, na obra A poética do espaço, para definir a relação do humano com seu lugar íntimo ou, como ele mesmo afirma, o espaço de nossa felicidade. Os reflexos da relação que o ser humano manteve com os lugares que habitou ressurgem, a todo momento, nas suas novas vivências, estimulando-o à criação de novos significados e imagens que resultam numa interação poética.

Quintás também oferece considerações importantes sobre a interação com o espaço, com a paisagem, pensando tal interação como um encontro, do qual nascem vínculos que sustentam o sentido de habitar:

Quando alguém percorre um bosque, ao divisar a ermida a vê nestes dois níveis - o objetivo e o lúdico - e faz a experiência de inter-relação viva à qual corresponde tal edifício e o qual encarna, a ermida adquire uma especial mobilidade, uma flexibilidade e um dinamismo peculiares. (...) $\mathrm{O}$ meio ambiente é visto como um conjunto de elementos que se interferem e se complementam. (QUINTÀS, 1992, p. 57)

A pretensão das operações do entendimento de dar estabilidade às coisas, na síntese intelectualista questionada por Merleau-Ponty, é, assim, relativizada na percepção primordial das coisas, nessa experiência de pertencimento do ser humano ao mundo vivido.

O fenômeno de percepção, diante dessas reflexões, ganha um importante significado: sua compreensão permite ao ser humano relativizar a rigidez de seus conhecimentos, a ânsia de tratar o mundo como algo diante dele, se oferecendo para ser esmiuçado e dominado. A natureza deixa de ser um filme a saciar-lhe o olhar e passa a envolvê-lo, oferecendo-lhe sua imensidão, seu poder de transformação, sua fluidez. Junto com ela, os lugares habitados passam a ser, como quer Quintás, uma riqueza de realidades valiosas a formar novos âmbitos de vivência. Convertem-se, natureza e espaço, no invisível que se dá à expressão e lhe inspira o poder da criação, como pensam Merleau-Ponty e Dufrenne. São a fluidez e o colorido imperando sobre a forma que, em Bachelard, alimentam a poética que ensina ao ser humano um novo modo de ver o mundo, de sentir, de pensar, de se expressar e de ser. 


\section{POSSÍVEIS SIGNIFICADOS PARA A EDUCAC̣ÃO AMBIENTAL}

Onde, portanto, a racionalidade desenvolvimentista impera, alterando modos de vida e mudando definitivamente paisagens e lugares concretos, criando, por vezes, os não-lugares ${ }^{1}$ e as hiper-realidades, vive um humano que pode estar desaprendendo o sentido de fazer parte, de estar imerso no mundo vivido. $O$ desencantamento do mundo e o desenraizamento do humano parecem se passar na mesma medida que a deseducação dos sentidos e a dessensibilização.

Ocorre também a exploração das imagens fora dos espaços concretos. Duarte Jr. assim define o tema da hiper-realidade ou do simulacro: "construções virtuais realizadas principalmente pelos meios de comunicação e que se superpõem, como sonho dourado, sobre a verdade endurecida do mundo real" (DUARTE JR., 2004, p. 19). O autor apresenta um processo "quase que de desmaterialização" da realidade por meio do qual tal realidade se converte em cenários virtuais, nos quais "se transaciona mais com imagens e signos do que com coisas concretas". Conclui que decorre daí um embrutecimento das capacidades sensíveis humanas, "um afastamento acentuado da natureza e a concepção do mundo como uma construção exclusiva da ciência e da tecnologia” (DUARTE JR., 2004, p. 216).

Daí deriva a dificuldade da educação ambiental em falar das transformações da relação ser humano-ambiente, sem cair nas malhas de imperativos morais, que marcam uma linguagem fatalista e ameaçadora, ou na redução de sentidos do termo sustentabilidade. Em muitos casos, o discurso da moralidade e da sustentabilidade pode ser facilmente reconhecido como ineficaz, justamente quando se sustenta na mesma lógica desenvolvimentista, artificializante dos modos de viver e homogeneizante das subjetividades. Essa lógica perpetua a ideia de substituições de adjetivos para uma mesma forma de ser, em essência: cidadão ecológico no lugar de cidadão consumista; paradoxalmente, produtos ecológicos no lugar de produtos prejudiciais; empresas verdes no lugar de empresas poluidoras; crescimento planejado no lugar de crescimento desordenado, etc. Essas persistências que ecoam nesses discursos apontam para uma fuga do enfrentamento dos desafios de mudanças bem mais profundas. O entendimento sobre a crise já é senso comum, mas as novas atitudes diante da vida e do outro não vêm. Os problemas perturbam pontualmente e de forma efêmera as consciências, 
mas o discurso não fundado em vivências estéticas criadoras impede a percepção de que o enfrentamento da crise passa pela transformação dos modos de ser e de viver. O sujeito, assim, não tem a condição básica para a criação de novos modos de interação: estar sensibilizado, isto é, desperto para as significações afetivas do encontro com o mundo, com os outros.

Considerando a experiência estética como indispensável à criação de sentidos de ambiente como sinônimo de lugar habitado e de novas subjetividades e modos de viver, chega-se a uma questão indispensável ao discurso e à práxis da gestão e educação ambiental: pensar o prejuízo da estesia, na história de vida dos habitantes dos grandes centros urbanos, seja quando são capturados pelas hiper-realidades, que os distancia de seus espaços concretos, seja quando assistem mudanças tão rápidas e drásticas na configuração da paisagem que lhes privam de elementos singulares para a significação estética e manutenção de laços de afetividade. Pensar esse prejuízo não significa tomar os rumos de uma radicalização em defesa do natural, um retorno romântico à natureza. Pelo contrário, reconhecê-lo talvez seja um ponto de partida para pensarmos modos de viver e uma construção do lugar habitado em que a vivacidade dos sentidos, despertada no prazer da experiência estética da natureza e no conforto psicológico dele derivado, esteja conjugada com a criatividade humana, que permite a criação de espaços repletos de significações, espaços de felicidade. Nesse sentido, a cultura não é subsumida na contemplatividade da natureza, mas busca nas vivências de plena interatividade com ela a sensibilização dos sentidos, por meio dos quais é possível reconhecer nos lugares cotidianos os cantos do mundo onde o impulso criativo do ser humano pode se expressar, cantos passíveis de se tornarem lugares amados. A natureza que "não cessa de improvisar" (DUFRENNE, 1998, p. 62) pode, assim, inspirar ao ser humano a possibilidade de recriar a cultura e redesenhar modos de viver.

Essa reflexão ganha contornos éticos quando constatamos que a exclusão do acesso à natureza e ao belo tem relação com as marcantes diferenças sociais. As discussões em torno dos problemas socioambientais estão focadas, na quase totalidade, em condições básicas de sobrevivência. No entanto, recentemente tem havido uma tendência clara a considerar que qualidade de vida é tudo que possa proporcionar uma vida melhor. As condições de saúde, renda, educação, nutrição, moradia, lazer, segurança, autorrealização das pessoas são alguns dos fatores considerados 
determinantes na qualidade de vida humana (HERCULANO, 1998). Apesar disso, as duas necessidades contempladas nos discursos das políticas emergenciais e, infelizmente, assistencialistas são a saúde e a alimentação.

Não é preciso dizer que essas necessidades básicas limitam a expectativa dos assistidos à sobrevivência, negando-se a priori as reais condições de vida e de felicidade. Note-se que saúde e alimentação são necessidades suscitadas da dimensão física do humano. Reflitamos que há outras dimensões do humano - psíquica, intelectual, espiritual, sensível -, que também geram necessidades que sequer são mencionadas. Essas dimensões é que estão na base da interação com os lugares habitados. Maffesoli (1996, p. 12-13) afirma que há momentos, no processo histórico de uma sociedade, em que a direção dada pelas determinações econômicas, políticas ou morais dão lugar às relações vividas no dia-a-dia, de maneira que o laço social se torna emocional: “(...) elabora-se um modo de ser (ethos) onde o que é experimentado com os outros será primordial". O autor denomina essa condição de "ética da estética": "decididamente, a estética (aisthesis), o sentir comum, parece ser o melhor meio de denominar o 'consenso' que se elabora aos nossos olhos, o dos sentimentos partilhados".

Aqui chegamos a um contexto em que se inserem os objetivos de nossas reflexões: não se discute a falta de acesso às condições de vivência que satisfaçam as necessidades estéticas e que educam a dimensão sensível. Em adição, a satisfação estética está relacionada à presença de elementos naturais, o que se revela na miscigenação da natureza com o belo imaginado e construído na arte e na arquitetura. E, como qualquer outra necessidade socioambiental, a vivência estética deveria permear os discursos inclusivos, deixando de ser considerada artigo de luxo para ser condição básica para a vida humana.

Assim como os problemas ambientais não atingem igualmente todo o espaço urbano, concentrando-se nos locais ocupados pelos menos favorecidos (COELHO, 2001, p. 29), a distribuição da condições que garantam acesso ao belo e conforto psicológico a seus habitantes não é homogênea. Enquanto a maioria das populações periféricas vive em ambientes deteriorados, grandes bosques e produções arquitetônicas estão ilhados em condomínios fechados. A isso soma-se o fato de que a especulação imobiliária se concentra em lugares com imagens 
paradisíacas, atribuindo posse a espaços originalmente públicos, o que resulta mudanças irreversíveis na paisagem.

É nesse sentido que a ressignificação do mundo da vida, a partir da experiência estética, passa a ser uma questão também educativa e social. É desafio para a educação ambiental chamar a atenção para a importância da necessidade estética para o ser humano e oportunizar-lhes vivências sensibilizantes. Isso significa, em outros termos, fundar um discurso ambientalista não na pura transmissão de novos conhecimentos ecológicos, mas em vivências significantes que suscitem reflexões sobre a lógica que sustenta um modelo de desenvolvimento profundamente enraizado nas construções sociais modernas. A lógica que funda os discursos ambientais ainda carrega o caráter de um finalismo, que é reflexo de uma política determinada pelos interesses econômicos. Segundo Duarte Jr. (2004, p. 98), “o modo de ver o mundo orienta-se movido pelas questões 'o que posso fazer com isto e que vantagens posso obter disso?', ao passo que o olhar estético não interroga, mas deixa fluir, deixa ocorrer o encontro entre a sensibilidade e as formas que lhe configuram emoções, recordações e promessas de felicidade”. A lógica centrada na emotividade e no pertencer a um lugar e encontrar-se no olhar do outro inauguraria, assim, um razão sensível coerente, mais que a razão instrumental, com as mudanças buscadas pela educação ambiental.

Não pretendíamos que esse caminho reflexivo nos levasse a inferências imediatas sobre uma prática pedagógica possível. Embora a visitação da concepção fenomenológica da percepção e da teoria estética nos inspire a visualizar possibilidades para a educação, o objetivo central de nosso estudo é gerar inquietações sobre o que definitivamente não poderá ser efetivado por uma educação que reproduza os princípios do pensamento clássico. E também a ineficácia de uma educação ambiental que continue a falar predominantemente pela lógica da razão numa mudança das formas de relação ser humano-ambiente, sem passar pela ressignificação desse encontro do sujeito com o mundo. Essa superação só será possível, a nosso ver, mediante a consideração de que toda educação ambiental é, necessariamente, educação estética.

\section{REFERÊNCIAS}

AUGÉ, M. Não-lugares: introdução a uma antropologia da super-modernidade. 4 ed. Campinas, SP: Papirus, 2004. 
BACHELARD, G. A poética do espaço. São Paulo: Martins Fontes, 1993.

BACHELARD, G. A água e os sonhos: ensaio sobre a imaginação da matéria. São Paulo: Martins Fontes, 1997.

CHAUÍ, M. Experiência do pensamento: ensaios sobre a obra de Merleau-Ponty. São Paulo: Martins Fontes, 2002.

COELHO, M.C.N. Impactos ambientais em áreas urbanas - teorias, conceitos e métodos de pesquisa. In: GUERRA, A.J.T.; CUNHA, S.B. (Orgs.). Impactos ambientais urbanos no Brasil. Rio de Janeiro: Bertrand Brasil, 2001.

DUARTE Jr, J. F. Fundamentos estéticos da educação. 2 ed. Campinas, SP: Papirus, 1988.

DUARTE Jr, J. F. O sentido dos sentidos: a educação (do) sensível. 3 ed. Curitiba: Criar Edições, 2004.

DUFRENNE, M. Estética e filosofia. 3 ed. São Paulo: Perspectiva, 2002.

HERCULANO, S. C. A qualidade de vida e seus indicadores. Ambiente e Sociedade, ano I, n. 2, p. 77-99, 1998.

MAFFESOLI, M. No fundo das aparências. Trad. Bertha Halpern Guravitz. Petrópolis, RJ: Vozes, 1996.

MERLEAU-PONTY, M. O olho e o espírito. In: MERLEAU-PONTY, M. Textos escolbidos. Trad. Marilena Chaú. São Paulo: Abril Cultural, 1984. p. 86-111. Coleção Os pensadores. MERLEAU-PONTY, M. Fenomenologia da percep̧̧ão. Trad. Carlos A.R. Moura. 2 ed. São Paulo: Martins Fontes, 1999.

MERLEAU-PONTY, M. Conversas. Trad. Fábio Landa e Eva Landa. São Paulo: Martins Fontes, 2004.

QUINTÁS, A. L. Estética. Trad. Jaime A.Classen. Petrópolis, RJ: Vozes, 1992.

RIBON, M. A arte e a natureza. Trad. Tânia Pellegrini. Campinas, SP: Papirus, 1991.

SCHOPENHAUER, A. O mundo como vontade e representação. Rio de Janeiro: Contraponto, 2001. SCHOPENHAUER, A. Metafísica do belo. Trad. Jair Barbosa. São Paulo: EdUNESP, 2003.

\section{NOTA}

${ }^{1}$ Segundo Augé (1994), a definição de lugar traz implícita uma relação direta com o histórico, com o relacional e com o identitário e, desta forma, o espaço por não possuir tais características relacionais deve ser encarado como não-lugar. Podemos exemplificálos com os espaços dos hipermercados e dos shopping centers.

Recebido: 30/03/2009

Aprovado: 29/06/2009

Contato:

Universidade Federal do Paraná (UFPA)

Departamento de Teoria e Prática de Ensino - Setor de Educação Rua General Carneiro 460 - $5^{\circ}$ andar - Centro

Curitiba - PR

CEP 80060-150 